\title{
Analysis on the Difference of Urban and Rural Preschool Education Development in China from the Perspective of Fairness
}

\author{
Zhang Aihua \\ Nanning Normal University, School of Education Science, Guangxi, Nanning, China
}

Keywords: fair view; urban and rural preschool education; development differences

\begin{abstract}
Preschool education is the initial stage of educational activities. It is also a basic educational activity for children. It is the cultivation of children's physical and psychological qualities in the early stages of their life development. It has an important impact on the learning activities when children entering school. This paper mainly analyzes and discusses the differences in the development of preschool education in urban and rural areas in China based on the perspective of fairness.
\end{abstract}

\section{Introduction}

Preschool education is an educational development stage that can be of a significant impact on children's physical and mental development. The development of preschool education in China has also developed rapidly with the development of the economy. However, due to the imbalance in economic development, the uneven distribution of educational resources and large numbers of people go to cities, the differences in preschool education development in urban and rural areas in China has gradually greater. This is very unfavorable to the healthy development of China's preschool education and the realization and guarantee of social justice. It is necessary to analyze the causes of the differences in the development of preschool education in urban and rural areas, and to find out the solutions to the problems.

\section{The reasons for the difference in the development of preschool education in urban and rural areas}

First, the disparity between urban and rural economic development has gradually increased. The development of productivity is the most important factor affecting the speed of human development. It also plays a decisive role in the development of education. The development of productivity in a country or region determines the level of economic development in this country or region, and determines the scale of investment in the development of education and the improvement of the construction of educational facilities ${ }^{[1]}$. If the daily food and clothing problems of residents in a country or region cannot be solved, it is impossible for the authorities and residents to spare efforts to develop education. Moreover, the more backward the economy is, the lower the overall quality of the local residents may be. It is difficult to really realize the importance and significance of education. This will fall into a vicious circle. The more backward the economy is, the more backward the minds of residents are. The more they fail to realize the significance and role of education, the more education is unable to be developed. The less the education develops, the less able the quality of the residents can be improved and the regional economy will fall behind. Therefore, the widening gap between urban and rural economic development is the main reason for the existence and expansion of the preschool education development in China.

Second, the allocation of urban and rural education resources is uneven ${ }^{[2]}$. The imbalance in the allocation of educational resources includes not only the imbalance in the construction of teaching facilities, but also the imbalance in the distribution of teachers, the degree of perfection in the construction of educational mechanisms, and the imbalance in the scale of investment in education. According to China's current social development, the urban economy is relatively developed, and all infrastructure construction is much more complete and richer than rural areas. Children have 
relatively more opportunities for education and development. Teachers with rich teaching experience and excellent teaching abilities are more willing to stay in a city with more opportunities, higher salary and greater development. On the other hand, China is still in the primary stage of socialist development. The development policy adopted by the Party and the government is“making people be rich first in some areas" and "making rich people help others to get rich ". In this process, as a priority construction and development object, the city has not only obtained the government's preferential policies for development, but also attracted a large number of personnel and labor population. In this way, it has accelerated the development and construction of the city, and at the same time, it has weakened the development dynamic resources of rural construction, making the rural education construction process very slow, and it is difficult to effectively supplement the educational resources and the gap in the development of preschool education in urban and rural areas has gradually widened.

Third, the start of preschool education is different. The start of preschool education development between urban and rural areas in China is different. In terms of starting time, the enlightenment education with the nature of preschool education of urban has existed since ancient times, and it is more obvious in modern times. The development of preschool education in rural areas in China started late, and it was greatly influenced by urban preschool education. The development of preschool education in rural areas of China has been almost none since modern times. Since the founding of the People's Republic of China, especially since the reform and opening up, formal preschool education in rural areas has been rapidly developed and constructed; In terms of educational content, preschool education in Chinese cities includes not only medical knowledge and basic knowledge, but also the cultivation of language learning (foreign language mainly) and art skills. Moreover, the development level of preschool education in these areas has been relatively perfect. The content of preschool education in rural areas of China is mainly based on some common sense of life and basic knowledge. Although the training of foreign languages and talents is also involved, it is still in the initial stage of development, and there are still many imperfections in all aspects of training mechanisms. Therefore, the difference start in development is also an important reason for the development of preschool education in urban and rural areas.

Fourth, the differences in the concept of urban and rural education ${ }^{[3]}$. The differences of educational concepts include the differences of educational concepts between educators, educators and families. The first is the education concept of educators. There are more opportunities for preschool educators in cities to access different educational concepts and educational methods, and there are more opportunities for exchanges. In rural areas, educators will fall behind people in urban areas when they come into contact with new educational concepts and educational methods. Therefore, preschool educators in urban areas are more likely to change their educational concepts and educational methods earlier. The time accepted in rural areas is generally later than in urban areas. Moreover, rural areas are more susceptible to be indirect influenced from urban teaching when they adopt new educational concepts and educational methods; The second is the educational concept of the educated. Generally speaking, the groups of children receiving preschool education are children from 3 to 7 years old. They are generally rich in imagination, but lack rigorous logical thinking and hands-on creativity. Children in urban areas are more influenced by foreign advanced concepts and things, and the content of education outside the school is often more than that of children of the same age in rural areas. Therefore, the attitude towards learning and the attitude towards different educational content and methods are different; The last is the differences in the concept of family education.For a long time, the concept of family education in rural areas is often more traditional and the form of expression is more serious and rigid. While, the concept of family education in urban areas reflects a modern educational ideology, they pay attention to the equal exchange of education between parents and children, pay attention to the needs and emotions of children, and the educational methods more reflect the factors of democracy, and which are easier for children to accept. 


\section{The necessity of reducing the development difference between urban and rural preschool education}

First, narrowing the differences in the development of preschool education in urban and rural areas is conducive to promoting education equity and ensuring that more children have equal rights to be educated and equal chance to accept education. For a long time, due to the existence and increasing of the differences in the development of preschool education in urban and rural areas, it is difficult for urban and rural children to enjoy equal access to education. More rural population enters the city. The number and scale of preschool education in cities are increasing. The pressure of preschool education in urban and rural areas has also increased. Urban preschool education is facing the problem of a sharp increase in the number of educational objects, but the educational measures are difficult to follow up effectively. The phenomenon of "insufficient supply" appeared in preschool education. The development of rural preschool education has gradually shrunk, the number of students has been decreasing, and there has been a phenomenon of "excessive supply". This has led to the aggravation of the inequity of education. Therefore, narrowing the development of preschool education in urban and rural areas is conducive to promoting education equity and maintaining social harmony and stability.

Second, narrowing the differences in the development of preschool education in urban and rural areas is conducive to improving the level of rural education and improving the educational concept in rural areas. According to the analysis above, the existence and increasing of preschool education differences between urban and rural areas and the development level of urban and rural education and educational concepts are in a relationship of complementing and promoting each other. Educational concepts and improvements promote the adjustment and improvement of educational methods and educational content, thereby improving the development level of rural preschool education. On the other hand, the higher the level of preschool education is, the improvement and renewal of educational concepts and educational methods in all aspects are also faster and more perfect, and the faster the development of education is, the difference in preschool education between urban and rural areas is getting smaller and smaller. It is conducive to the healthy development of preschool education in urban and rural areas in China.

Third, narrowing the differences in the development of preschool education in urban and rural areas is the development requirement of China's socialist system and the comprehensive construction of a well-off society. China is a socialist country led by the working class and based on the alliance of workers and peasants. The ultimate development goal is to achieve common prosperity. On the other hand, China is in the primary stage of socialist development and is in the strategic development period of building a well-off society in an all-round way. In this critical period, we must take the scientific development concept and the realization of the Chinese dream as the ideological guidance, strive to narrow the differences in urban and rural development, ensure social equity, and realize the grand goal of building a well-off society in an all-round way at an early date ${ }^{[4]}$.

\section{Suggestions on narrowing the development of preschool education in urban and rural areas}

According to the analysis of the reasons for the differences in the development of preschool education in urban and rural areas, narrowing the gap between preschool education in urban and rural areas requires consideration and improvement from the following aspects:

First, accelerating the development of rural economy and improve the level of rural economic development. The economy is the material economic foundation for social construction. Accelerating the development of rural economy and improving the speed and level of rural economic development are the basic conditions for narrowing the development of preschool education in urban and rural areas. In order to accelerate the development of rural economy, the government should increase the preferential policy support and financial support for the development of rural areas, set up more rural development projects, let the capital of the city flow more to the rural areas, and promote the harmonious development of the urban and rural 
economy; In order to accelerate the development of rural economy, on the one hand, rural areas must clearly define their own development orientation, and formulate scientific and rational development plans based on the actual development of the region. On the other hand, it is necessary to absorb more construction talents in various aspects, adjust the unreasonable economic structure, formulate scientific development plans in line with local characteristics, realize the diversified development of regional economy, and ensure the rational allocation of economic and educational investment.

Secondly, the government should play the role of macro regulation and control, increase the support for the development of rural preschool education, and ensure the equitable allocation of educational resources. First, they should adjust the proportion of financial support for preschool education in urban and rural areas, appropriately increase financial support for rural preschool education, and help improve the infrastructure construction of preschool education in rural areas; Second, it is necessary to strengthen the support for making preschool education in rural areas more like the construction of educational mechanisms, such as the standardization of preschool education and teaching content in rural areas, the improvement of rural preschool education management system and supervision system, to provide institutional guarantees for the development of preschool education in rural areas. Third, they could provide more talents for the development of preschool education in rural areas, such as adding some policy incentives for preschool education in rural areas, and regularly organizing some training, learning and exchange activities for preschool educators in rural areas. In short, the increase should support the construction and development of preschool education in rural areas from all angles of education construction and development.

Finally, increasing publicity and learning, increasing urban and rural exchanges, and improving preschool education concepts. In this regard, urban areas should respond to the government's relevant policy calls, consciously to burden social responsibilities, strengthen support for preschool education in rural areas, and increase financial support, institutional support, and talent experience support for preschool education development in rural areas. For example, some teaching experience exchange meetings can be held to allow preschool educators in urban and rural areas to exchange teaching and class management experience; On the other hand, rural areas should take the initiative to implement the "going out" strategy. They should combine the local cultural characteristics and the actual situation of education development, learn the advanced education and teaching concepts and experiences in other countries or regions, and formulate preschool education development plans, preschool education methods and contents that are in line with local development and characteristics. To achieve accelerating development without losing the characteristics, and there are both content and form of innovative preschool education development.

\section{Conclusion}

Preschool education is the most important development period before children enter primary school. It has a profound impact on the development of children. Schools, families and society must pay attention to it. According to the current development situation of urban and rural preschool education in China, understanding the differences in the development of urban and rural areas and the reasons for the differences in preschool education in our country, analysis from different angles and different subjects of responsibility and solve problems properly is an important method to narrow the development of preschool education in urban and rural areas as soon as possible.

\section{References}

[1] Caiqin Zhuang. Analysis on the difference of urban and rural preschool education development in China from the perspective of fairness[J]. Western China Quality Education, 2016, 2(7):121-121.

[2] Fan Yang. Analysis on the difference of urban and rural preschool education development in China from the perspective of fairness[J]. Journal of Shangqiu Vocational and Technical Colleges, 2016, 15(1):128-130.

[3] Xiaomin Fu. Analysis on the difference of urban and rural preschool education development in 
China from the perspective of fairness[J]. New Educational era, 2017(42).

[4] Juan Zhong. Analysis of the differences in the development of preschool education between urban and rural areas in the perspective of fairness[J]. Education, 2016(11):00173-00173. 